\title{
A Sir2-Like Protein Participates in Mycobacterial NHEJ
}

\author{
Zhongdao $\mathrm{Li}^{1,2}$, Jikai Wen ${ }^{3}$, Yaning Lin ${ }^{4}$, Shihua Wang ${ }^{4}$, Peng Xue ${ }^{5}$, Zhiping Zhang ${ }^{1}$, Ying Zhou ${ }^{5}$, Xiao \\ Wang $^{6}$, Li Sui ${ }^{6}$, Li-Jun $\mathrm{Bi}^{5 *}$, Xian-En Zhang ${ }^{1 *}$
}

1 State Key Laboratory of Virology, Wuhan Institute of Virology, Chinese Academy of Sciences, Wuhan, China, 2 Graduate School, Chinese Academy of Sciences, Beijing, China, 3 School of Biosciences, University of Birmingham, Edgbaston, Birmingham, United Kingdom, 4 College of Life Sciences, Fujian Agriculture and Forestry University, Fuzhou, China, $\mathbf{5}$ National Laboratory of Biomacromolecules and Proteomics Platform, Institute of Biophysics, Chinese Academy of Sciences, Beijing, China, $\mathbf{6}$ Department of Nuclear Physics, China Institute of Atomic Energy, Beijing, China

\begin{abstract}
In eukaryotic cells, repair of DNA double-strand breaks (DSBs) by the nonhomologous end-joining (NHEJ) pathway is critical for genome stability. In contrast to the complex eukaryotic repair system, bacterial NHEJ apparatus consists of only two proteins, Ku and a multifunctional DNA ligase (LigD), whose functional mechanism has not been fully clarified. We show here for the first time that Sir2 is involved in the mycobacterial NHEJ repair pathway. Here, using tandem affinity purification (TAP) screening, we have identified an NAD-dependent deacetylase in mycobacteria which is a homologue of the eukaryotic Sir2 protein and interacts directly with $\mathrm{Ku}$. Results from an in vitro glutathione S-transferase (GST) pull-down assay suggest that Sir2 interacts directly with LigD. Plasmid-based end-joining assays revealed that the efficiency of DSB repair in a sir2 deletion mutant was reduced 2 -fold. Moreover, the $\Delta$ sir2 strain was about 10 -fold more sensitive to ionizing radiation (IR) in the stationary phase than the wild-type. Our results suggest that Sir2 may function closely together with Ku and LigD in the nonhomologous end-joining pathway in mycobacteria.
\end{abstract}

Citation: Li Z, Wen J, Lin Y, Wang S, Xue P, et al. (2011) A Sir2-Like Protein Participates in Mycobacterial NHEJ. PLoS ONE 6(5): e20045. doi:10.1371/ journal.pone.0020045

Editor: Shuang-yong Xu, New England Biolabs, Inc., United States of America

Received January 9, 2011; Accepted April 11, 2011; Published May 26, 2011

Copyright: (C) $2011 \mathrm{Li}$ et al. This is an open-access article distributed under the terms of the Creative Commons Attribution License, which permits unrestricted use, distribution, and reproduction in any medium, provided the original author and source are credited.

Funding: This work was supported by the National Protein Research Fund (Grant No: 2009CB825402, 2009CB522605 and 2006CB910902), the Chinese Academy of Sciences (Grant No: KSCX2-YW-R-164 and KSCX1-YW-R-63), the National Natural Science Foundation of China (Grant No: 30970590) and the Key Project Specialized for Infectious Diseases from the Chinese Ministry of Health (2008ZX10003-005). The funders had no role in study design, data collection and analysis, decision to publish, or preparation of the manuscript.

Competing Interests: The authors have declared that no competing interests exist.

*E-mail: blj@sun5.ibp.ac.cn (L-JB); x.zhang@wh.iov.cn (X-EZ)

\section{Introduction}

DNA double-strand breaks (DSBs) are the most lethal form of DNA damage and pose the greatest threat to genomic DNA integrity $[1,2]$. They are caused by a variety of endogenous cellular processes and exogenous factors. All organisms have a range of cellular pathways that repair DSBs. Two major pathways, namely homologous recombination (HR) and nonhomologous end-joining (NHEJ), have evolved to repair DSBs and maintain genetic integrity $[3,4,5,6]$. The latter is utilized in higher eukaryotes and is a complex pathway, involving many components such as DNAPKcs, the Ku70/80 heterodimer, Ligase IV, XRCG4, Artemis, and XLF/Cernunos $[7,8]$. Proteins of this pathway are critical for maintaining mammalian genomic stability.

Compared with the eukaryotic NHEJ pathway, the prokaryotic NHEJ system has only two known components. Reports have indicated that the two core proteins, $\mathrm{Ku}$ and LigD, are sufficient for NHEJ repair in vitro $[9,10]$, and transformation of yeast with $\mathrm{Ku}$ and LigD can successfully reconstitute NHEJ in vivo [9]. LigD is a multifunctional protein composed of polymerase (PolDom), nuclease (NucDom) and ligase (LigDom) domains [11], and each domain can exert its function independently during the process of DNA end joining. Generally, prokaryotic NHEJ is initiated at double-strand breaks by the recruitment of $\mathrm{Ku}$ that binds to each of the DNA ends, which will further recruit LigD through its PolDom [11] to the DNA damage site for the DNA end processing and ligation. The PolDom specifically recognizes the $5^{\prime}$ phosphate group [12] and mediates the synapsis before resection, resynthesis, and ligation of DSBs. The NucDom subsequently resects the nonextendable $3^{\prime}$ termini if required, and the PolDom and LigDom will then re-synthesize and ligate the nicks. The core proteins of $\mathrm{Ku}$ and $\mathrm{LigD}$ were well studied; however, many details of the prokaryotic NHEJ pathway are unclear [13,14]. Many of the bacteria that possess NHEJ repair apparatus, for example Mycobacterium tuberculosis (Mtu), are major human pathogens. They spend much of their life-cycle in host organisms in the stationary phase, and their DNA repair capacity plays a crucial role in resisting the host response to infection, suggesting that they may rely on NHEJ during prolonged periods of no homologous recombination when homologous templates are lacking $[15,16]$. It has been reported that the Mycobacterium smegmatis (Msm) $\Delta k u$ mutant is significantly more sensitive to IR during the stationary phase than the wild-type, providing further evidence of the importance of the NHEJ pathway for survival [17]. Recently, Sinha et al [18] found a novel Ku-binding partner of UvrDl and identified its role in DSB repair in mycobacteria. Mycobacterial UvrD1, a DNA-dependent ATPase I and helicase II, also participates in the nucleotide excision repair (NER) pathway [19] which indicates that some DNA repair proteins might participate in more than one process. It seems likely, therefore, that there may be more additional NHEJ components in mycobacteria yet to be discovered.

Tandem affinity purification (TAP) combined with mass spectrometry has been demonstrated to be an effective and 
reliable strategy for identifying and purifying protein complexes under native conditions in different organisms [20,21]. It is a generic two-step affinity purification protocol for isolating TAP-tagged proteins together with their associated proteins. The yeast-based TAP procedure [22] for isolating protein complexes makes use of sitespecific recombination to introduce a dual-tagging cassette into specific chromosomal loci. Mycobacteria do not readily recombine exogenous linear DNA fragments into their chromosomes due to their high rate of illegitimate recombination relative to homologous DNA exchange, but expression of the Che9c, gp60 and gp61 proteins from the mycobacterial recombineering system markedly enhances integration [23]. Here we have applied this system to M. smegmatis in order to look for additional components in the mycobacterial NHEJ pathway. We identified Sir2, a novel Ku-binding protein and investigated the interactions between Sir2 and Ku using a glutathione S-transferase (GST) pull-down assay, a common approach for studying protein-protein interactions. As anticipated, we discovered that Sir2 also interacts with LigD, and thus postulate that these three components likely form a ternary complex. Results from the analysis of NHEJ efficiency in a sir2 mutant show for the first time that Sir2 is involved in mycobacterial NHEJ.

\section{Results}

\section{Generation and characterization of a knock-in strain expressing the TAP-tagged Ku protein}

To search for potential components of the mycobacterial NHEJ apparatus, we used TAP combined with mass spectrometry to identify components of protein complexes that interact with $\mathrm{Ku}$. By using overlap extension PCR combined with a mycobacterial homologue recombination system, a TAP-tag knock-in cassette was introduced at the end of the coding region of $\mathrm{Ku}$. The principle is shown in Figure 1. The recombinant strain was screened by PCR (Figure S1) and confirmed by DNA sequencing. Expression of the recombinant $\mathrm{Ku}$ protein was verified using a peroxidase anti-peroxidase (PAP) complex antibody that binds the ProtA moiety of the TAP tag (Figure S2). This strain was then used for TAP purification as described below.

Identification of Sir2 as a new Ku-binding protein by TAP

To identify $\mathrm{Ku}$ binding partners, we performed TAP in $M$. smegmatis using the constructed Ku-TAP knock-in strain. After separation by SDS-PAGE, Ku binding proteins were visualized by silver staining (Figure 2) and identified by mass spectrometry. Mass spectral data were searched using SEQUEST against NCBI $M$. smegmatis protein database and results were filtered and displayed using the Bioworks 3.2. Of the proteins identified with mass spectrometry, only the protein with more than one peptide identified by mass spectrometry was NAD-dependent deacetylase (MSMEG_5175). Furthermore, an independent replication of the TAP experiment (Figure S3) can only identify this deacetylase protein again. So this protein was selected for subsequent experiments. Protein sequence alignment indicated that NADdependent deacetylase was highly homologous with Sir2 family proteins (Figure S4) and it was named MsmSir2. Moreover, the result of a phylogenetic tree analysis revealed that MsmSir2 had more homology with SIRT5 of mammalian Sir2 family than with yeast Sir2 (Figure S4). Our results suggest that MsmSir2 is a novel interaction partner of $\mathrm{Ku}$ in prokaryotic cells and may be involved in NHEJ in mycobacteria.

\section{Sir2 interacts directly with $\mathrm{Ku}$ and LigD}

To further investigate the interaction between Sir2 and Ku, an in vitro GST pull-down assay was performed. A bacterially-expressed

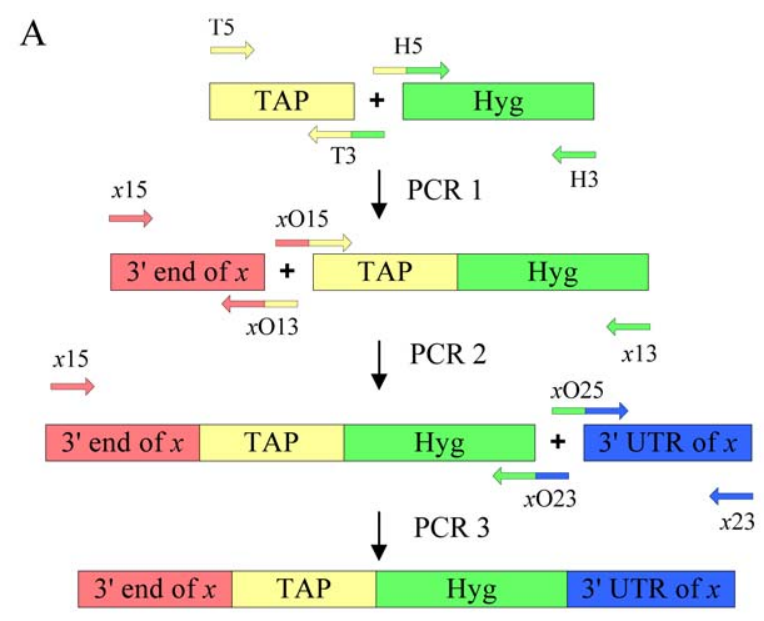

B
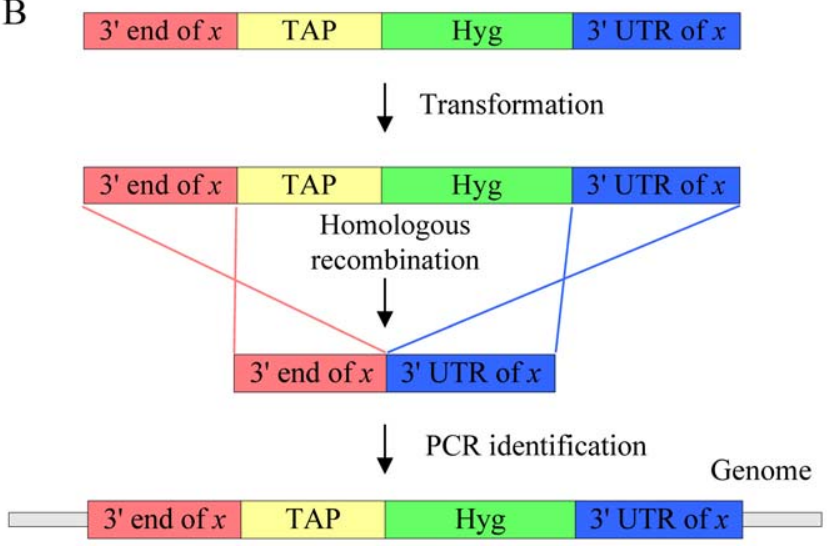

Figure 1. Construction of the TAP-tag knock-in cassette and targeting to a specific gene locus. (A) The TAP-tag knock-in cassette was constructed by three rounds of overlap extension PCR. During the first round of PCR (PCR1), the knock-in core cassette was generated by fusing together the TAP-tag (TAP) gene and the hygromycin ( $\mathrm{Hyg}$ ) gene using four primers $\mathrm{T} 5, \mathrm{~T} 3, \mathrm{H} 5$ and $\mathrm{H} 3$ (Table S1). During the following two rounds of PCR, the $3^{\prime}$ end of $x$ and $3^{\prime}$ UTR of $x$ were inserted adjacent to the $\mathrm{N}$ - and $\mathrm{C}$-terminus of the knock-in core fragment during PCR2 and PCR3, respectively, generating the full length TAP-tag knock-in cassette. The primers used in PCR2 and PCR3 are shown in Table S1. $x$ indicates the gene to be TAP tagged. (B) The TAP-tag was integrated into the C-terminal coding region of each gene using recombineering methods as described in the materials and methods.

doi:10.1371/journal.pone.0020045.g001

GST-MsmSir2 fusion protein was immobilized on glutathione beads and incubated with purified His-MsmKu protein. Western blotting indicated that Sir2 interacts directly with $\mathrm{Ku}$ (Figure 3A). Thus, the interaction observed with the TAP method can also be reconstituted in vitro. That Sir2 also interacts directly with $\mathrm{Ku}$ from M. tuberculosis was confirmed by the same strategy (Figure 3B).

Since the core of the prokaryotic NHEJ apparatus consists of $\mathrm{Ku}$ and LigD in interaction with each other, the interaction between Sir2 and LigD must be addressed when determining the function of Sir2 in the NHEJ. As shown in Figure 4, the interaction between Sir2 and LigD protein was confirmed by GST pull-down.

Sir2 is involved in the mycobacterial NHEJ pathway

As mentioned above, Sir2 interacts with both $\mathrm{Ku}$ and $\mathrm{LigD}$ in mycobacteria, suggesting its involvement in the mycobacterial 


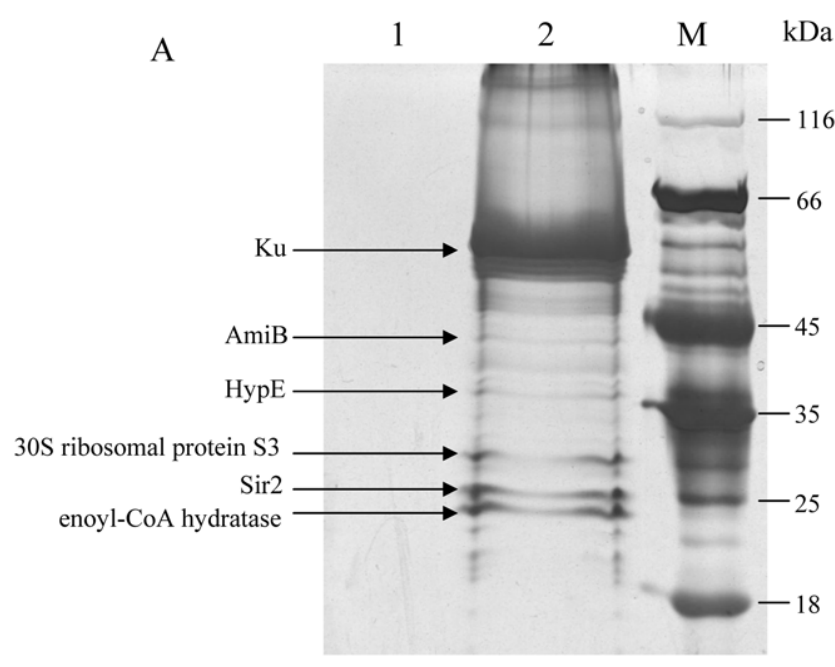

B

\begin{tabular}{cc}
\hline Protein & Peptides \\
\hline \multirow{2}{*}{ Sir2 } & R.VVTQNIDDLHER.A \\
& R.TVAAWEDHLDVR.V \\
& R.ETASEALPTLLQR.L \\
\hline
\end{tabular}

Figure 2. Identification of Sir2 as a Ku-binding protein. (A) Ku (TAP-tagged at the C-terminus) was purified by affinity chromatography with Protein $A$ and calmodulin. Protein complexes were visualized by silver staining after separation by SDS-PAGE. Several specific bands were excised and subjected to mass spectrometry. Lane 1, the TAP tag alone as a control; lane 2, TAP-tagged Ku complex; M, Protein molecular weight marker. (B) The Sir2 peptides were identified by mass spectrometry.

doi:10.1371/journal.pone.0020045.g002

NHEJ pathway. A plasmid-based in vivo end-joining assay was applied to study the NHEJ pathway in a sir2-deficient strain (Figure S5 and S6). The $k u$-deleted strain (Figure S5 and S6) was constructed as a control to evaluate this NHEJ assay method. These mutant strains were generated with a mycobacterial recombineering system [23]. As shown in Figure 5A, the $k u$ deletion strain exhibited different deficiencies in the repair of the three DSB end structures $(P$-value $<0.01)$, consistent with previous reports [24]. The overall efficiency of end-joining in the $\Delta$ sir2 mutant was two-fold lower compared with the wild-type strain while the fidelity of NHEJ between the $\Delta$ sir 2 mutant and the wildtype strain had no apparent difference, suggesting the involvement of Sir2 in prokaryotic NHEJ efficiency.

In order to further test the role of Sir2 protein in mycobacterial NHEJ, we explored the effect of IR on wild type, sir2- or $k u$ deficient strains. As expected, $k u$-deficient cells were extremely sensitive to IR in the stationary phase (Figure 6), consistent with Ku's role in NHEJ. Moreover, sir2-deficient cells also presented marked sensitivity to IR in the stationary phase (Figure 6), confirming that Sir2 is involved in the NHEJ pathway. Furthermore, the survival curves (Figure 7) show that irradiated $\Delta$ sir2 stationary phase cells had about a 10 -fold reduction in viability compared to wild-type cells, further confirming that Sir2 plays a role in bacterial NHEJ. In addition, the viability of wild-

\section{input GST GST-MsmSir2}

A

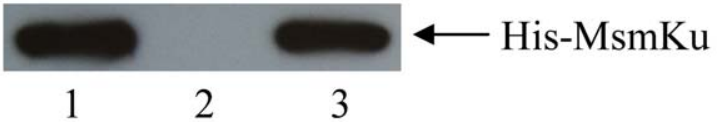

input GST GST-MtuSir2

B

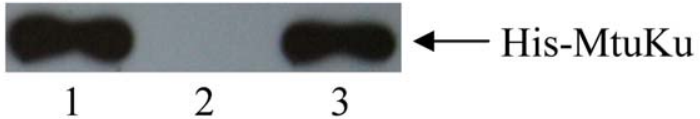

Figure 3. Use of GST pull-down to confirm that Sir2 interacts with Ku. (A) GST pull-down assay. Glutathione sepharose beads were incubated with $2 \mu \mathrm{g}$ of GST-MsmSir2 (lane 3) or GST (lane 2), followed by incubation with $0.2 \mu \mathrm{g}$ of His-MsmKu. The bound proteins were probed with an anti-His-tag antibody. Lane 1 contains $20 \mathrm{ng}(10 \%$ of the total input) of His-MsmKu. (B) GST pull-down assay was also conducted on Sir2 and Ku from M. tuberculosis. Glutathione sepharose beads bound with GST-MtuSir2 (lane 3) or GST (lane 2) were incubated with His-MtuKu. The bound proteins separated by SDS-PAGE were analyzed by Western blotting using an anti-His-tag antibody to detect His-tagged MtuKu. Lane 1 contains $20 \mathrm{ng}$ (10\% of the total input) of His-MtuKu.

doi:10.1371/journal.pone.0020045.g003

type and sir2- or ku-deficient strains was affected to a similar extent when exposed to irradiation during the logarithmic phase (Figure 7). It is known that NHEJ is required for prokaryotic DSB repair in the stationary phase $[17,25]$; the above evidence that the $\Delta$ sir2 strain was more sensitive to IR in the stationary phase than in the log phase when compared to the wild-type further indicates that Sir2 protein plays a role in NHEJ. Taken together, these results therefore provide strong evidence supporting the hypothesis that Sir2, like $\mathrm{Ku}$, is involved in the mycobacterial NHEJ pathway during the stationary phase.

\section{input GST GST-MsmSir2}

A

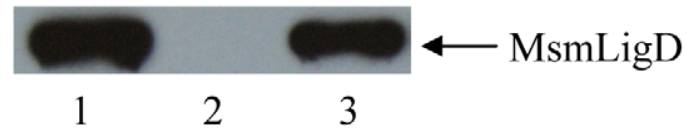

\section{input GST GST-MtuSir2}

$\mathrm{B}$

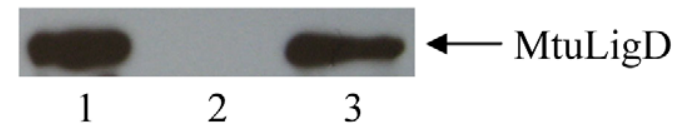

Figure 4. In vitro interactions between Sir2 and LigD detected by the GST pull-down assay. (A-B) GST pull-down was used to identify the interaction between Sir2 and LigD in M. smegmatis and $M$. tuberculosis. (A) Glutathione sepharose beads were incubated with $2 \mu \mathrm{g}$ of GST-MsmSir2 (lane 3) or GST (lane 2), followed by incubation with $0.2 \mu \mathrm{g}$ of His-MsmLigD. The bound proteins were probed with an antiHis-tag antibody. Lane 1 contains 20 ng (10\% of the total input) of HisMsmLigD. (B) Glutathione sepharose beads were incubated with $2 \mu \mathrm{g}$ of GST-MtuSir2 (lane 3) or GST (lane 2), followed by incubation with $0.2 \mu \mathrm{g}$ of His-MtuLigD. The bound proteins were probed with an anti-His-tag antibody. Lane 1 contains $20 \mathrm{ng}$ (10\% of the total input) of His-MtuLigD. doi:10.1371/journal.pone.0020045.g004 


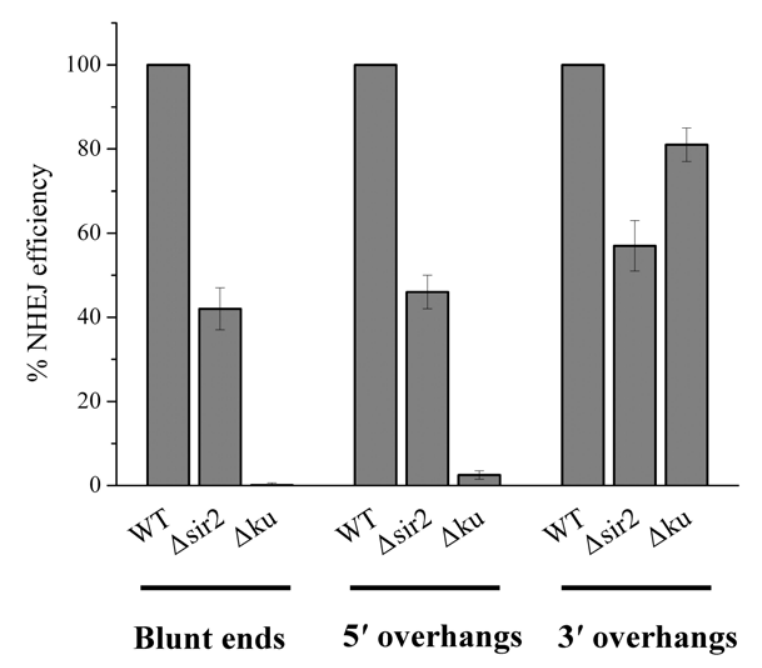

$\mathrm{B}$

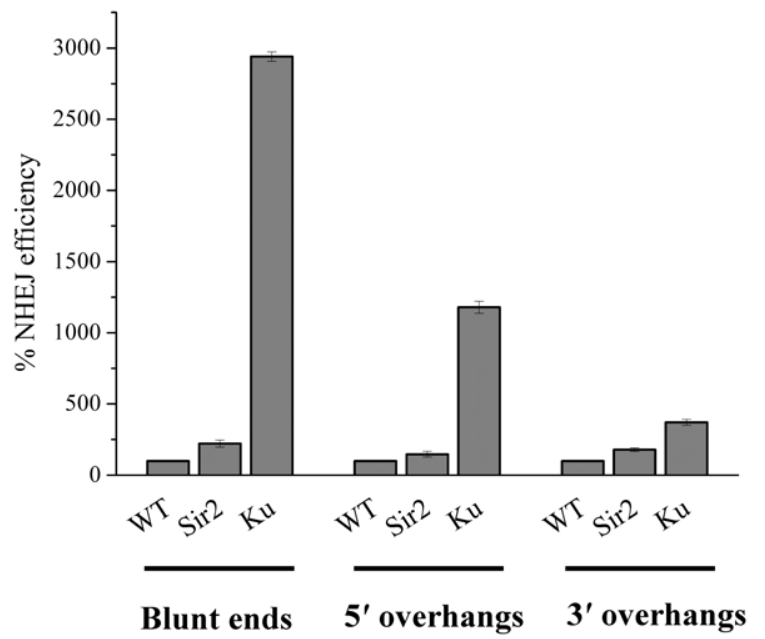

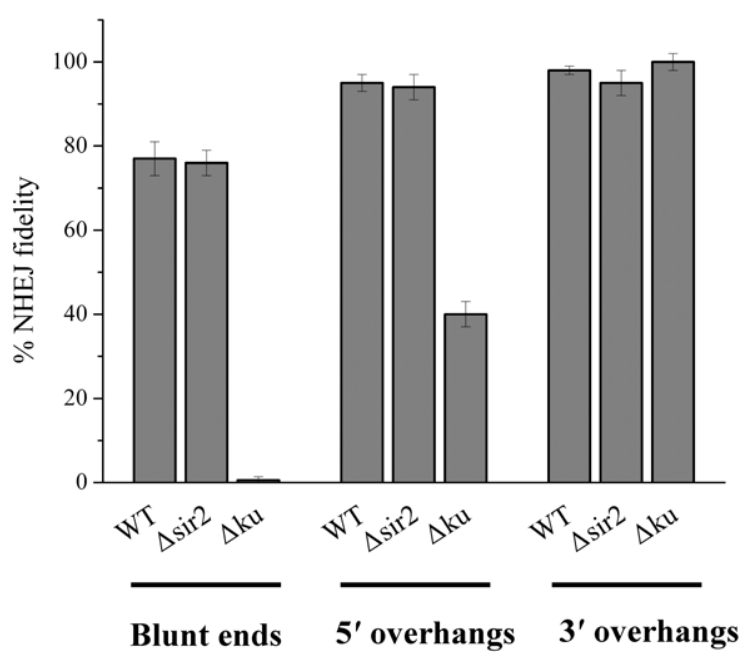

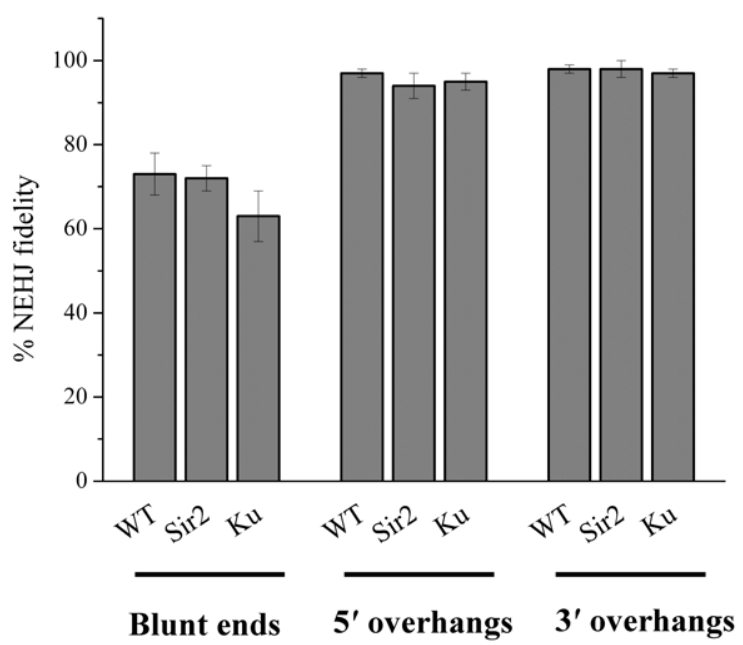

Figure 5. Sir2 is involved in the mycobacterial NHEJ pathway. (A) The sir2-deficient strain had reduced NHEJ activity. The sir2 deletion strains were transformed linear plasmids with three types (blunt, $5^{\prime}$ overhang and $3^{\prime}$ overhang) of DSBs. NHEJ efficiency and fidelity were calculated as described in the materials and methods ( $P$-value for statistical significance is less than 0.01). (B) Overexpression of Sir2 enhanced NHEJ activity. Using a similar in vivo plasmid-based NHEJ assay, strains overexpressing Sir2 or Ku were transformed with the above three types of linear plasmids $(P$ value $<0.05)$.

doi:10.1371/journal.pone.0020045.g005

\section{Overexpression of Sir2 protein stimulates NHEJ}

To further investigate whether overexpression of Sir2 had any influence on NHEJ, the wild-type $\mathrm{mc}^{2} 155$ carrying a pJRL-Sir2 overexpression plasmid, and control cells with an empty pJRLC vector, were electroporated with a linearized hygromycin-resistant NHEJ assay plasmid. Ku protein was also overexpressed by the
pJRL- $k u$ plasmid. The influence of $\mathrm{Ku}$ and Sir2 on NHEJ activity was analyzed by counting colony numbers and recording colony color after incubation for $3 \mathrm{~d}$ at $37^{\circ} \mathrm{C}$. As shown in Figure $5 \mathrm{~B}$, the efficiency of repairing blunt, $5^{\prime}$ overhang, and $3^{\prime}$ overhang DSBs all increased two-fold in Sir2-overexpressing cells compared with that in control cells, which once again demonstrated the significant 


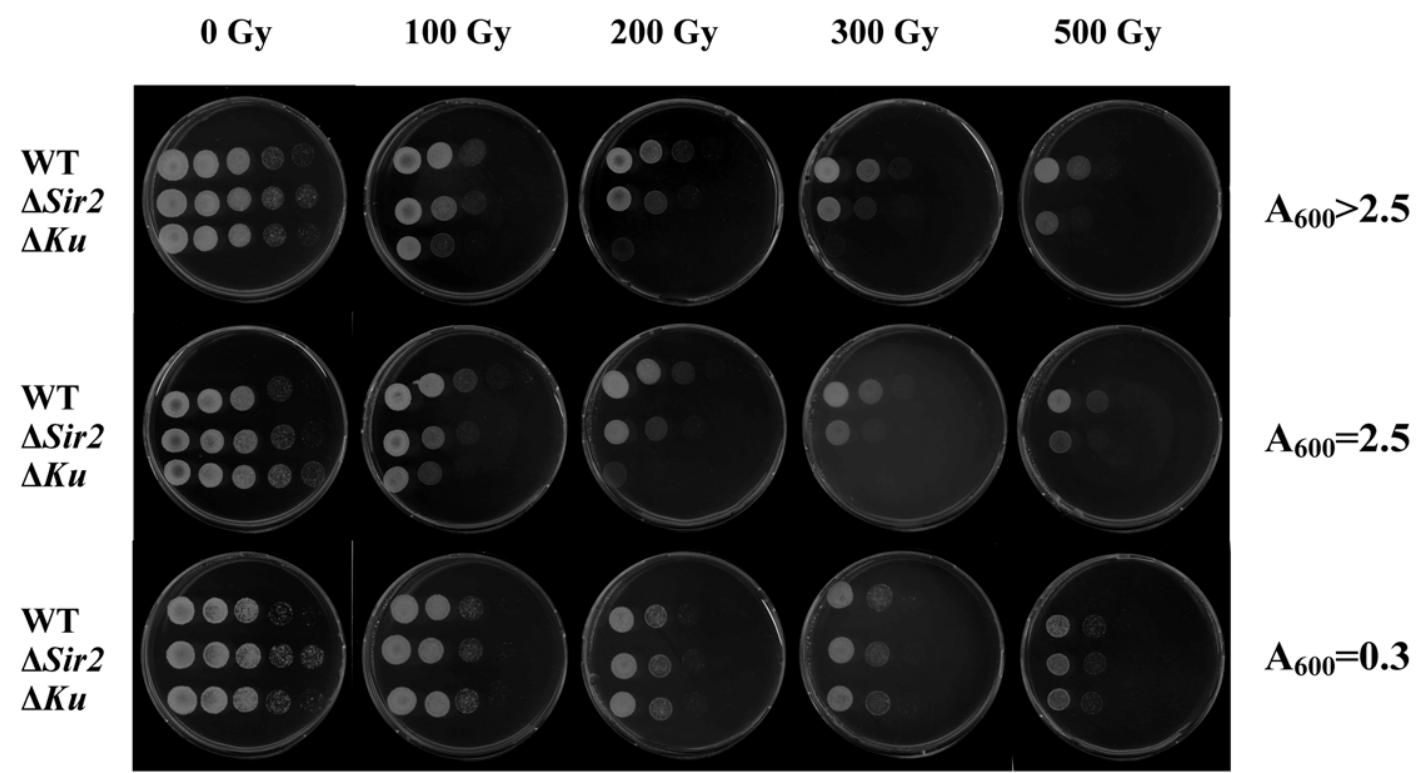

Figure 6. IR sensitivity of sir2- or ku-deficient strains. Cultures of wild-type, $\Delta s i r 2$ and $\Delta k u$ strains of $M$. smegmatis were harvested in the log phase $\left(A_{600}=0.3\right)$, stationary phase $\left(A_{600}=2.5\right)$ or late stationary phase $\left(A_{600}>2.5\right)$. After irradiation using a ${ }^{60} \mathrm{Co}$ source at a dose rate of $14 \mathrm{~Gy} / \mathrm{min}$, serial dilutions $\left(10^{-1}-10^{-4}\right)$ of cultures were spotted $(20 \mu \mathrm{l})$ onto $7 \mathrm{H} 10$ plates. The plates were incubated at $37^{\circ} \mathrm{C}$ for 3 days. Results presented are representative of three replicate experiments.

doi:10.1371/journal.pone.0020045.g006

role that Sir2 plays in the end-joining process. NHEJ efficiency was enhanced dramatically when Ku was overexpressed, showing its essential role in the prokaryotic NHEJ pathway. Nonetheless, the overall fidelity of the Sir2- or the Ku-overexpressing strain was not affected.

We next used Western blotting to examine whether the effect of overexpressed Sir2 on NHEJ was correlated with its regulation of $\mathrm{Ku}$ protein expression. The TAP-tag knock-in Ku and Sir2 strains were transformed with pJRL-Sir2 and pJRL-Ku, respectively, and the empty pJRLG vector was transformed into each TAP-tagged strain as a control. An anti-ProtA antibody was used in Western blotting analysis to detect TAP-tagged $\mathrm{Ku}$ or Sir2. As shown in Figure 8A, there were no apparent differences in the Sir2 protein level between control cells and $\mathrm{Ku}$-overexpressing cells. In contrast, overexpression of Sir2 protein reduced the amount of $\mathrm{Ku}$ protein. These results suggest that Sir2 expression downregulated $\mathrm{Ku}$ expression.

We also used quantitative real-time PCR to analyze Sir2 and $\mathrm{Ku}$ mRNA levels. The Sir2 (or $\mathrm{Ku}$ ) mRNA levels in wild-type cells did not change significantly after the overexpression of $\mathrm{Ku}$ (or Sir2) (Figure 8B). These results suggest that $\mathrm{Ku}$ does not participate in the regulation of Sir2 at the mRNA level, and vice versa.

\section{Discussion}

The eukaryotic NHEJ system has been extensively studied and has a growing list of new components. In recent years, emerging research on the prokaryotic NHEJ system is focusing on the DNA binding protein $\mathrm{Ku}$ and the multifunctional protein LigD, but additional factors involved in the end-joining process remain obscure. Using the yeast two-hybrid system, Sinha et al [18] identified UvrD1, a novel protein interacting with $\mathrm{Ku}$, shedding light on the bacterial NHEJ mechanism by identifying the involvement of alternative proteins. As $M$. tuberculosis spends prolonged periods in non-replicating states within macrophages, the NHEJ system is thought to be an important pathway for its survival in the human body. A deeper understanding of the mycobacterial NHEJ mechanism will help in developing strategies for combatting this pathogen.

This is the first time that the TAP system, a powerful protein purification technique, has been applied in M. smegmatis. Using this method, a NAD-dependent deacetylase (MSMEG_5175) named MsmSir2 was identified as a novel $\mathrm{Ku}$ binding protein that is involved in the mycobacterial NHEJ system. MsmSir2 has high similarity with eukaryotic Sir2. It has been reported that the Sir2/ 3/4 complex interacts physically with the NHEJ proteins Yku70 [26] and Yku80 [27] in vivo, and that Sir4p plays a major role in the initiation of the interaction process and recruits Sir2p and Sir3p [28]. Interestingly, we found that MsmSir2 interacts directly with $\mathrm{MsmKu}$ and $\mathrm{MsmLigD}$ in vitro. All the above interactions were also observed between $\mathrm{Sir} 2$ and $\mathrm{Ku}$ and $\mathrm{LigD}$ from $M$. tuberculosis. Therefore, our results suggest that Sir2 forms a ternary complex between $\mathrm{Ku}$ and $\mathrm{LigD}$, implying that Sir2 plays an important biological role in NHEJ.

In yeast cells, Sir2 has been reported to take part indirectly in the eukaryotic NHEJ pathway, and affects end-joining efficiency by regulating expression of mating-type genes (HMRa and $H M L \alpha$ ) $[29,30]$. Mutations in SIR genes cause the haploid a- or $\alpha$ - mating type cells to have the nonmating phenotype of a/ $\alpha$ diploids. $\mathrm{Sir}^{-}$ haploid cells lacking mating-type genes have the same NHEJ efficiency as $\mathrm{Sir}^{+}$strains. However, the silent mating-type genes $H M L \alpha$ and HMRa are not present in mycobacteria and the function of Sir2 may not be completely the same from bacteria to human despite highly conserved. Thus MsmSir2 possibly affects bacterial NHEJ by an alternative mechanism. Results from our plasmid-based in vivo NHEJ assay clearly suggest the existence of a NHEJ pathway in M. smegmatis involving Sir2, but suggest that the role of Sir2 in NHEJ is not as crucial as that of Ku. A probable explanation for this is that the DSBs of the DNA substrate were the complementary sequences generated by restriction enzyme digestion and could be readily ligated. Thus $\mathrm{Ku}$ and LigD were 

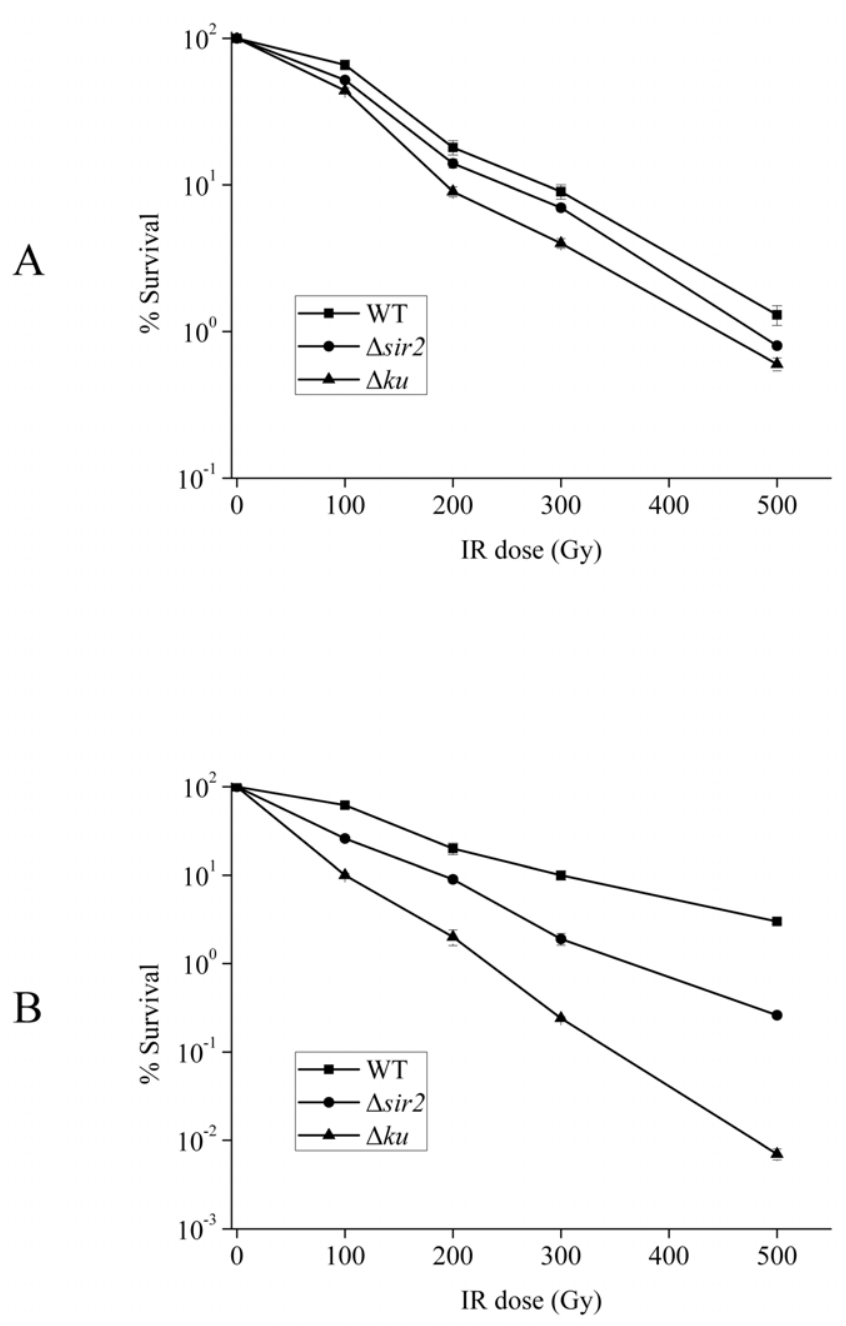

Figure 7. Cell survival after ionizing radiation. Cells in the log or stationary phases were exposed to $\gamma$-irradiation at the doses indicated. Cell survival was measured as described in the Materials and methods. (A) Log phase cultures of wild-type, $\Delta s i r 2$ and $\Delta k u$ strains of $M$. smegmatis were sensitive to ionizing radiation to a similar extent. (B) Sensitivity of wild-type, $\Delta s i r 2$ and $\Delta k u$ stationary phase cultures to ionizing radiation. $\Delta$ sir2 and $\Delta k u$ strains were more sensitive to ionizing radiation than the wild-type $(P$-value $<0.05)$.

doi:10.1371/journal.pone.0020045.g007

sufficient to repair these linear plasmids. However, Sir2 probably accelerates the repair process by facilitating the recruitment of $\mathrm{Ku}$ and LigD at the DSB, since a lower level of $\mathrm{Ku}$ protein was required for efficient NHEJ when Sir2 was overexpressed. In order to produce more DNA DSBs in vivo, IR was utilized for further verification of the role of Sir2 in the NHEJ pathway. IR analysis revealed that the $\Delta$ sir 2 strain was around 10 -fold more sensitive to IR in the stationary phase than the wild-type strain, suggesting that it has a role in DNA DSB repair after severe DNA damage to cells. Given the ternary complex of $\mathrm{Sir} 2 / \mathrm{Ku} / \mathrm{LigD}$ and the reduction in NHEJ efficiency in the sir2-deficient strain, Sir2 could be a regulator which serves as a scaffold for recruiting $\mathrm{Ku}$ and LigD to promote NHEJ activity.

In this study, depletion or overexpression of Sir2 affected NHEJ efficiency, suggesting that Sir2 plays a role in mycobacterial NHEJ. Interestingly, overexpression of Sir2 causes a low level of $\mathrm{Ku}$ protein, indicating that there is an elaborate regulation or feedback mechanism that balances the expression of particular proteins in the NHEJ machinery. Although the overexpression of Sir2 seems to be able to compensate for the reduced expression of $\mathrm{Ku}$ protein in NHEJ, the amount of $\mathrm{Ku}$ mRNA was not affected by the overexpression of Sir2. Likewise the mRNA level of Sir2 was not affected by the overexpression of $\mathrm{Ku}$. Thus, regulation of the amount of these proteins appears to take place during protein translation. These regulatory mechanisms require further investigation.

\section{Materials and Methods}

\section{Strains and culture conditions}

The $M$. smegmatis $\mathrm{mc}^{2} 155$ strain and its derivatives were grown at $37^{\circ} \mathrm{C}$ on ADC-containing Middlebrook $7 \mathrm{H} 10$ medium (Difco). Strains grown in liquid medium were shaken in Middlebrook 7H9 broth (Difco) supplemented with ADC enrichment media (Difco). When required, $100 \mu \mathrm{g} / \mathrm{ml}$ hygromycin B (Roche Diagnostics) or $20 \mu \mathrm{g} / \mathrm{ml}$ kanamycin (Sigma) was used.

\section{Construction of plasmids}

The coding sequences of Sir2 in M. tuberculosis and M. smegmatis were amplified by PCR and then cloned into the pGEX-6P-1 vector at the BamHI-XhoI site to generate the fusion plasmids pGEX-6P-1-MtuSir2 and pGEX-6P-1-MsmSir2, respectively. Similarly, the open reading frames encoding $\mathrm{Ku}$ and $\mathrm{LigD}$ were cloned respectively into pQE30 and pET28a vectors at different sites (Table 1), generating the pQE30-MtuKu and pQE30$\mathrm{MsmKu} \mathrm{Ku}$ expression plasmids and the pET28a-MtuLigD and pET28a-MsmLigD LigD expression plasmids. Genomic DNA was isolated and purified with a Genomic DNA Isolation Kit (Omega) according to the manufacturer's instructions. All the plasmids were extracted using a Plasmid DNA Kit (Omega) according to the protocol provided. All the above plasmids were used in the pulldown assay.

For the in vivo plasmid-based NHEJ assay, lacZ reporter plasmids were constructed according to Aniukwu et al [24] with slight modifications. Briefly, the promoter of Rv2642 was first amplified from genomic DNA with PCR primers tagged with KpnI and XbaI restriction sites located $5^{\prime}$ and $3^{\prime}$ to the gene, respectively. The amplified fragment was then cloned into the pJV53 vector (a gift from Dr Graham F. Hatfull, University of Pittsburgh, USA), generating $\mathrm{pJVR}$. Subsequently, the lac $Z$ gene encoding $\beta$ galactosidase was amplified from genomic DNA of Eccoli strain AB1157 (kindly provided by the Coli Genetic Stock Center, Yale University) and cloned into the $\mathrm{pJVR}$ vector using $\mathrm{XbaI}$ and NheI restriction sites engineered into the primers. A PstI restriction enzyme site was introduced into the forward primer and the plasmid was named pJRL. As plasmid pJRL contains an intact lac $Z$ gene, it was first linearized with a suitable restriction enzyme before NHEJ analysis, since uncut circular plasmids containing functional lac Z genes would affect the analysis of NHEJ fidelity. In order to avoid this problem and improve the accuracy of the analysis of NHEJ fidelity, a foreign DNA fragment from combination of the part of ssb and ligD gene of $M$. smegmatis with the HindIII site at the junction was inserted into the lac Z gene. This 1.6-kbp EcoRV fragment with an EcoRV site engineered into the primers in each end of the fragment was inserted into the single EcoRV site of pJRL, generating the pJRLE reporter plasmid. Similarly, the XbaI and PstI fragments were inserted into pJRL at the corresponding sites introduced as described above, generating the pJRLX and pJRLP reporter plasmids, respectively. For overexpression analysis, the hygromycin B gene was amplified from plasmid pSMT3 (kindly provided by Dr. Marcus A. Horwitz, University of California Los Angeles, USA) with PCR primers 


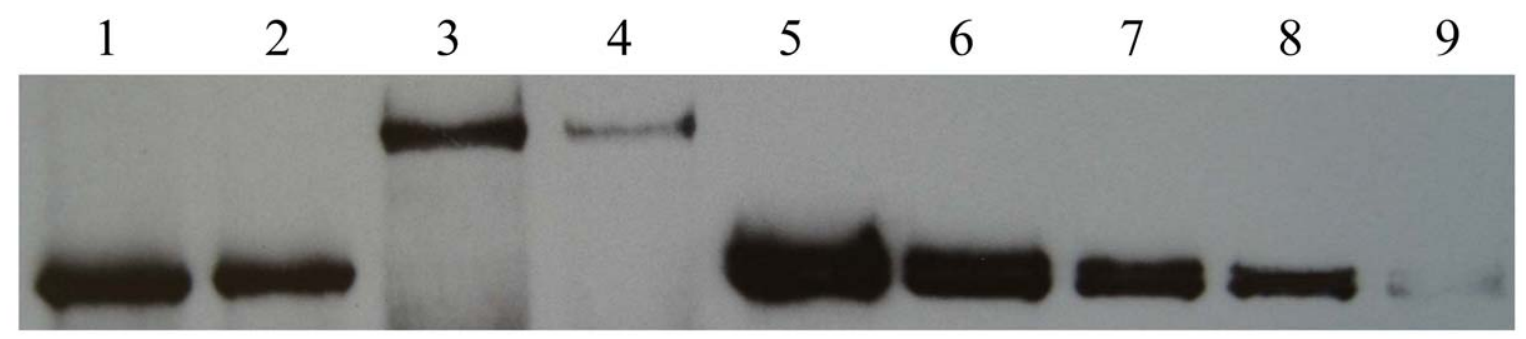

B

\begin{tabular}{ccc}
\hline $\begin{array}{c}\text { Protein } \\
\text { overexpressed }\end{array}$ & $\begin{array}{c}\text { Relative mRNA levels } \\
\text { sir2 }\end{array}$ \\
\hline Sir2 & 0.7 & 52 \\
$\mathrm{Ku}$ & 20 & 0.8 \\
\hline
\end{tabular}

\begin{tabular}{ccc}
\hline \multirow{2}{*}{ Deficient gene } & Relative mRNA levels \\
& $k u$ & $s i r 2$ \\
\hline sir2 & 2.0 & - \\
$k u$ & - & 2.2 \\
\hline
\end{tabular}

Figure 8. Overexpression of Sir2 reduced the Ku protein level independently of its mRNA level. (A) Western blotting of the protein level of Sir2 (or Ku) after the overexpression of Ku (or Sir2). Lane 1, Sir2-TAP-tagged strain; lane 2, Sir2-TAP-tagged strain overexpressing Ku; lane 3, Ku-TAPtagged strain; lane 4, Ku-TAP-tagged strain overexpressing Sir2; lanes 5-9 contains 15, 10, 5, 1 and $0.1 \mu$ M purified TAP-Sir2 protein, separately. After 3 days incubation at $37^{\circ} \mathrm{C}$, the cells were harvested and cell concentration was calculated by measuring the absorbance of the culture at UV $600 \mathrm{~nm}$. Cell lysates prepared from the same cell number were loaded onto the SDS-PAGE gel. Meanwhile, purified TAP-Sir2 that loaded onto the gel with a linear concentration gradient was used as control for the semi-quantitative analysis of Sir2 (or Ku) protein expression. (B) Real-time PCR analysis of the ku (or sir2) mRNA level when Sir2 (or ku) was overexpressed (left panel) or deleted (right panel). The quantitative data are the ratio of mRNA expression of one gene ( $k u$ or sir2) when the other one was overexpression or deleted relative to the wild-type cells after normalization against the 16S rRNA (rrsA) gene. doi:10.1371/journal.pone.0020045.g008

Table 1. Primers used in plasmid construction.

\begin{tabular}{|c|c|c|}
\hline Plasmid & Primer sequence $\left(5^{\prime}-3^{\prime}\right)$ & Restriction site \\
\hline pQE30-MsmKu & TITGGATCCATGAACCGTGCGGTACGCCATA & BamHI \\
\hline pQE30-MsmKu & AAAAAAGCTTCTACGACTTCTTCGCAGCTG & HindIII \\
\hline pQE30-MtuKu & TITTGGATCCATGCGAGCCATTTGGAC & BamHI \\
\hline pQE30-MtuKu & AAAAAAGCTTTCACGGAGGCGTTGGGACGT & HindllI \\
\hline pGEX-6P-1-MsmSir2 & CGCTGGATCCATGCAAGTTACTGTGCTCA & BamHI \\
\hline pGEX-6P-1-MsmSir2 & TTAACTCGAGTCAGGCCGAGCGGTTGAG & Xhol \\
\hline pGEX-6P-1-MtuSir2 & TAAAGGATCCATGCGAGTGGCGGTGCTCA & BamHI \\
\hline pGEX-6P-1-MtuSir2 & TATACTCGAGCTATTTCAGCAGGGCGGGCA & Xhol \\
\hline pET28a-MsmLigD & TATAGGATCCATGGAGCGCTATGAGCGGGTT & BamHI \\
\hline pET28a-MsmLigD & GTCGCAAGCTTCTATTCCCACACAACCTCATC & HindIII \\
\hline pET28a-MtuLigD & ATTAGGATCCATGGGTTCGGCGTCGGAGCAACG & BamHI \\
\hline pET28a-MtuLigD & TCGAGAAGCTTTCATTCGCGCACCACCTCACTG & HindIIII \\
\hline
\end{tabular}


tagged with SpeI and NheI restriction sites. The amplified fragments were then respectively cloned into the pJRL, pJRLE, pJRLX and pJRLP plasmids, generating the pJRLH, pJRLHE, pJRLHX and pJRLHP plasmids for the NHEJ assay in Ku/Sir2 overexpressing strains.

To construct plasmids for overexpression analysis, sir2 was PCR-amplified and cloned into the pJVR vector using XbaI and NheI restriction enzyme sites engineered into the primers to generate pJVR-Sir2. pJVR-Ku and pJVR-LigD were constructed in a similar manner to overexpress $\mathrm{Ku}$ and LigD, respectively. All cloning products were verified by sequencing.

\section{Construction of the TAP-tag knock-in cassette and its insertion into the C-terminus of ku}

The TAP (protA/CBP) tag (kindly provided by Dr. Jikai Wen, University of Birmingham, UK) consists of two immunoglobulinbinding domains of protein $\mathrm{A}$, a cleavage site for the tobacco etch virus (TEV) protease, and the calmodulin-binding peptide (CBP). A knock-in cassette was generated by splicing the TAP-tag gene upstream of the selectable marker gene using overlap extension PCR. The 500 bp upstream and downstream sequences of the $k u$ gene at the $3^{\prime}$ termini site termed kua $\left(3^{\prime}\right.$ end of $k u$ ) and kub ( $3^{\prime}$ UTR of $k u$ ) were then amplified by PCR. The kua and kub fragments were inserted adjacent to the N-terminus and Cterminus respectively by overlap extension PCR as described above, to form the final linear targeting substrate (Figure 1). The primers used to generate the Knock-in cassette are shown in Table S1. Subsequently, we used recombineering methods [23] to knockin the TAP tag flanking the C-terminus of $k u$. Briefly, the linear substrate was introduced into cells containing the recombineering plasmid pJV53 by electroporation, and the cells were allowed to recover for $4 \mathrm{~h}$ while shaking at $37^{\circ} \mathrm{C}$ before being plated onto $7 \mathrm{H} 10$ agar. The $k u$-TAP fusion gene was examined by PCR (Table $\mathrm{S} 2$ ) and cells expressing $\mathrm{Ku}$-TAP-tag fusions were validated by Western blotting. The TAP-tag gene was cloned into the plasmid pSMT3 at the BamHI-HindIII site to generate the fusion plasmid expressing TAP-tag protein as a control for Western blotting.

\section{Tandem affinity purification}

A $2 \mathrm{~L}$ culture of $M$. smegmatis cells was grown at $37^{\circ} \mathrm{C}$ for 3 days. After harvesting, cell pellets were washed once with lysis buffer (10 mM Tris-HCl pH 7.9, $0.15 \mathrm{M} \mathrm{NaCl}, 10 \%$ (v/v) glycerol, $0.2 \%(\mathrm{v} / \mathrm{v})$ Nonidet P-40, $1 \mathrm{mM}$ PMSF) and pelleted again. All subsequent steps were carried out at $4^{\circ} \mathrm{C}$. Cell pellets resuspended in lysis buffer were broken up by sonication, and a crude cytoplasmic extract was obtained from the soluble fraction after centrifugation at $16,000 \mathrm{~g}$ for $1 \mathrm{~h}$. The supernatant was added to a Polyprep column (Bio-Rad, Hercules, CA) with a $200 \mu \mathrm{l}$ bed volume of IgG-Sepharose 6 Fast Flow beads (Pharmacia) and rotated for $2 \mathrm{~h}$ at $4^{\circ} \mathrm{C}$. The resin was washed three times with lysis buffer, and twice with TEV buffer $(1 \mathrm{mM}$ DTT and $0.5 \mathrm{mM}$ EDTA in lysis buffer). Bound complexes were cleaved from the matrix with 100 units of TEV protease (Invitrogen, Carlsbad, CA) in $1 \mathrm{ml} \mathrm{TEV}$ cleavage buffer while rotating the column overnight at $4^{\circ} \mathrm{C}$ and then recovered by elution. Subsequently, the eluate was diluted with $3 \mathrm{ml}$ of calmodulin binding buffer $(10 \mathrm{mM}$ Tris$\mathrm{HCl}$ pH 7.9, $0.15 \mathrm{M} \mathrm{NaCl}, 1 \mathrm{mM} \mathrm{MgCl} 2,1 \mathrm{mM}$ imidazole, $0.1 \%$ (v/v) Nonidet P-40, $10 \mathrm{mM} \beta$-mercaptoethanol and $2 \mathrm{mM} \mathrm{CaCl} 2$ ) plus $3 \mu \mathrm{l}$ of $1 \mathrm{M} \mathrm{CaCl}_{2}$, and transferred to a Polyprep column containing $0.2 \mathrm{ml}$ calmodulin affinity resin (Pharmacia) equilibrated with calmodulin binding buffer. After incubation for $2 \mathrm{~h}$ at $4^{\circ} \mathrm{C}$, the matrix was washed four times with $10 \mathrm{ml}$ of calmodulin binding buffer and eluted with $1.5 \mathrm{ml}$ of calmodulin elution buffer (10 mM Tris-HCl pH 7.9, 0.15 M NaCl, 10 mM EGTA). The final eluate was concentrated by acetone precipitation and dissolved with $10 \mu \mathrm{l}$ sodium dodecyl sulfate (SDS) loading buffer. After boiling, the protein sample was separated by SDSpolyacrylamide gel electrophoresis (SDS-PAGE) and silver stained with a PlusOne silver staining kit (GE Healthcare) according to the manufacturer's protocol.

\section{Mass spectrometric analysis}

Individual protein bands were excised from polyacrylamide gels, digested with trypsin, and analyzed by liquid chromatographytandem mass spectrometry. MS data were searched using SEQUEST against NGBI $M$. smegmatis protein database and results were filtered and displayed using the Bioworks 3.2.

\section{Construction of $M$. smegmatis sir2 and $k u$ null mutants}

$M$. smegmatis strain null alleles were constructed by replacing the bulk of the open reading frame of each gene with the hygromycin $\mathrm{B}$ resistance gene using a mycobacterial recombineering system [23]. Briefly, the allelic exchange substrates were constructed as described above by overlap extension PCR. The allelic exchange substrate for every ORF was constructed by PCR amplification of approximately $500 \mathrm{bp}$ corresponding to the upstream and downstream regions, and was subsequently inserted adjacent to the hygromycin-resistance gene by overlap extension PCR. The primers used for amplifying the left and right arms of the knockout substrate for every gene are listed in Table S3. All gene disruptions were tested by PCR using flanking DNA sequences as primers and were further confirmed by DNA sequencing of the PCR products and Southern blotting. The primers used for the PCR analysis are listed in Table S4.

\section{Southern blotting}

To confirm the constructed sir2 and $k u$ mutants, genomic DNA was isolated from M. semgmatis wild-type and sir2 and $k u$ mutants using a genomic DNA isolation kit (Omega) and then digested with PstI restriction enzymes. Fragments containing the 5' flanking region of the sir2 or $k u$ gene, labeled with DIG using a DIG High Prime DNA Labeling Kit (Roche), were used as probes. Southern blotting was performed using a DIG High Prime DNA Detection Kit (Roche) according to the manufacturer's protocol.

\section{Protein expression and purification}

Plasmids used for pull-down assays were all transformed into BL21 (DE3) cells. Each transformed clone was cultured in $750 \mathrm{ml}$ $\mathrm{LB}$ medium at $37^{\circ} \mathrm{C}$ until the $\mathrm{A}_{600}$ reached 0.5. After diluting to a final concentration of $0.4 \mathrm{mM}$ IPTG, the culture was incubated for a further $10 \mathrm{~h}$ at $20^{\circ} \mathrm{C}$ with constant shaking. Harvested cell pellets were washed once with water and stored at $-80^{\circ} \mathrm{C}$. The MtuKu and MsmKu genes were inserted into separate pQE30 vectors and expressed in $E$. coli. The resulting His-tagged proteins were purified using Ni-NTA resin (GE Healthcare). Proteins bound to the resin were equilibrated with $50 \mathrm{ml}$ of binding buffer (20 mM Tris-HCl pH 7.9, $10 \mathrm{mM}$ imidazole and $500 \mathrm{mM} \mathrm{NaCl}$ ). After washing with washing buffer $(20 \mathrm{mM}$ Tris-HCl pH 7.9, $80 \mathrm{mM}$ imidazole and $500 \mathrm{mM} \mathrm{NaCl}$ ), proteins were eluted with $300 \mathrm{mM}$ imidazole. Similarly, MtuLigD, MsmLigD were purified using the above methods. Purified proteins were dialyzed against dialysis buffer (50 mM Tris-HCl pH 7.5, $200 \mathrm{mM} \mathrm{NaCl}$, and $20 \%$ glycerol). After dialysis and concentration, the proteins were stored either short-term at $-20^{\circ} \mathrm{C}$ or long-term at $-80^{\circ} \mathrm{C}$.

MtuSir2-GST, MsmSir2-GST and GST alone were purified using glutathione-Sepharose $4 \mathrm{~B}$ beads (GE Healthcare). After washing with buffer A (20 mM Tris- $\mathrm{HCl}$ pH 7.5, $500 \mathrm{mM} \mathrm{NaCl}$ 
and $10 \%$ glycerol), the proteins were eluted with buffer B $(10 \mathrm{mM}$ reduced glutathione, $50 \mathrm{mM}$ Tris-HCl $\mathrm{pH} 7.5$ and $500 \mathrm{mM}$ $\mathrm{NaCl})$. The purified proteins were analyzed by $12 \%$ SDS-PAGE. Protein concentration was determined using the Coomassie Bradford method (Thermo Scientific Pierce) with bovine serum albumin as the standard.

\section{GST pull-down assays}

The purified MsmSir2-GST protein $(20 \mu \mathrm{g})$ or the GST protein itself $(20 \mu \mathrm{g})$ was incubated with $40 \mu \mathrm{l}$ of glutathione-Sepharose $4 \mathrm{~B}$ beads in $500 \mu \mathrm{l}$ of buffer A (50 mM Tris-HCl pH 7.5, $200 \mathrm{mM}$ $\mathrm{NaCl}$, and $10 \%$ glycerol) with rotation at $4^{\circ} \mathrm{C}$ for $2 \mathrm{~h}$. After washing five times with $1 \mathrm{ml}$ of buffer A containing $0.1 \%$ Nonidet $\mathrm{P}-40$, the beads were then incubated with purified $\mathrm{Ku}$ protein $(20 \mu \mathrm{g})$ at $4^{\circ} \mathrm{C}$ for $8 \mathrm{~h}$. Finally, after extensive washing, all bound protein was eluted by boiling the beads in $40 \mu \mathrm{l}$ of $2 \times \mathrm{SDS}$ loading buffer and resolved by $12 \%$ SDS-PAGE for subsequent visualization by Western blotting. The immunoblot was probed with a monoclonal antibody directed against the His tag (1:2000 dilution) and with an anti-GST antibody (1:2000 dilution). The pull-down assay was used to investigate the other protein-protein interactions in the same way.

The protein-protein interactions between LigD and Sir2 were also analyzed using the GST pull-down assay described above.

\section{Preparation of substrate DNA}

The plasmids (pJRL, pJRLE, pJRLX and pJRLP) used in the in vivo NHEJ assay were constructed according to Aniukwu et al [24] with slight modifications. Briefly, the digestion sites designed to generate defined double strand breaks were XbaI (5' overhangs), PstI ( $3^{\prime}$ overhangs), and EcoRV (blunt end). The plasmids (pJRLH, pJRLHE, pJRLHX and pJRLHP) for the NHEJ assay in Sir2/Ku-overexpressed strains were hygromycin resistant instead of kanamycin resistant.

To generate the linear DNA substrates with different end, the plasmids above were digested with appropriate enzyme (XbaI, PstI or EcoRV), and then digested with HindIII that cuts within the foreign DNA fragment. The linearized fragments were isolated and purified from the gel using a Promega gel-extraction kit. The DNA concentration was determined by UV spectrophotometry (Thermo-spectronic).

\section{Evaluation of DSB repair efficiency and fidelity using the in vivo DNA end-joining assay}

To document the role of Sir2 in mycobacterial NHEJ in vivo, we employed a plasmid-rejoining assay. The NHEJ assay was performed as described previously [24]. Briefly, cells were electroporated with between 10 and $100 \mathrm{ng}$ linearized plasmid DNA or between 5 and $50 \mathrm{ng}$ uncut circular plasmid and then incubated in $1 \mathrm{ml} \mathrm{LB}$ medium at $37^{\circ} \mathrm{C}$, and rotated at $170 \mathrm{rpm}$ for $3 \mathrm{~h}$. A portion of the transformation mixtures was then plated in triplicate on LB agar medium containing $20 \mu \mathrm{g} / \mathrm{ml}$ kanamycin and $50 \mu \mathrm{g} / \mathrm{ml} \mathrm{X}$-gal. $100 \mu \mathrm{g} / \mathrm{ml}$ hygromycin was added to the above medium for overexpression assays. Plates were incubated for 3 days at $37^{\circ} \mathrm{C}$, and colonies were counted manually. Efficiency and fidelity were calculated according to Aniukwu et al [24]. Each experiment was repeated at least five times.

\section{lonizing radiation (IR) assays}

Irradiation was carried out using a ${ }^{60} \mathrm{Co}$ source at a dose rate of $14 \mathrm{~Gy} / \mathrm{min}$. Cultures were collected in the log phase, stationary phase, or late-stationary phase (corresponding to the different $\mathrm{A}_{600}$ units indicated in Figure 6). Following 100, 200, 300 and 500 Gy irradiation, aliquots of 10 -fold gradient dilutions were spotted onto 7H10 Middlebrook agar (Difco). In a separate experiment serially diluted samples from the log phase or stationary phase were plated on 7H10 Middlebrook agar (Difco), and colonies were counted after 3 days incubation at $37^{\circ} \mathrm{C}$. Non-irradiated samples of each cell type were used as controls in both experiments. Each experiment was repeated three times.

\section{Western blotting}

Western blotting was used for detecting TAP protein expression; proteins were electrophoresed on $12 \%$ SDS-polyacrylamide gels and transferred by electroblotting to $0.2 \mathrm{~mm}$ PVDF membranes (GE, Healthcare). Hybridizations with antibodies were performed according to the manufacturer's recommendations. The primary antibody used was a peroxidase anti-peroxidase complex (1:2000, catalogue number P1291; Sigma-Aldrich) for detecting the protA tag. Bound primary antibody was detected and visualized via incubation with a secondary HRP-linked anti rabbit IgG (1:5000, GE, Healthcare) and chemiluminescent substrate (ECL-plus substrate, GE, Healthcare). Western blotting in the GST pulldown assays was similar to that described above except that the primary antibody was an anti-his-tag antibody and the secondary antibody was an HRP-linked anti-mouse IgG.

\section{RNA extraction}

RNA was isolated from $20 \mathrm{ml}$ cultures of wild-type $M$. smegmatis $\mathrm{mc}^{2} 155, \Delta$ sir 2 and $\Delta k u$ mutant strains, and M. smegmatis $\mathrm{mc}^{2} 155$ carrying different plasmids (pJRL-Sir2, pJRL-Ku, pJRLG). Bacteria were pelleted, then resuspended in $1 \mathrm{ml}$ of lysis buffer and placed in a Lysing Matrix A tube. Lysis was performed in a FastPrep-24 instrument for $45 \mathrm{~s}$ at $6500 \mathrm{rpm}$. The aqueous phase was extracted with $200 \mu \mathrm{l}$ chloroform, and the RNA was precipitated with isopropanol. After washing in 70\% ethyl alcohol, the RNA was eluted in $40 \mu \mathrm{l}$ of RNase-free water. Chromosomal DNA contamination was removed from the eluted total RNA by treatment with DNase I (MBI Fermentas), followed by heat inactivation of the enzyme. The digested products were then reverse-transcribed with random hexamer primers (MBI Fermentas) to generate cDNA according to the manufacturer's recommendations.

\section{Quantitative real-time PCR}

Quantitative real-time PCR was performed with the SYBR Green PCR kit (Qiagen) on a Rotor-Gene 6000 instrument (Corbett Life Science). $20 \mu \mathrm{l}$ reactions were set up according to the standard protocol. Sequences of each primer are given in Table S5. All reactions were performed in triplicate. Reactions were heated to $95^{\circ} \mathrm{C}$ for $10 \mathrm{~min}$ followed by cycling for 45 cycles of $95^{\circ} \mathrm{C}$ for $15 \mathrm{~s}, 58^{\circ} \mathrm{C}$ for $15 \mathrm{~s}$, and $72^{\circ} \mathrm{C}$ for $15 \mathrm{~s}$. At the end of the PCR, melting curve analysis was performed and PCR products were analyzed on an agarose gel to ensure product specificity. The mRNA expression level for each target gene was normalized to the 16S rRNA gene (rrsA) expression level.

\section{Supporting Information}

Figure S1 Construction of $M$. smegmatis strains expressing TAP-tagged Ku or Sir2. Validation of TAP-tagged $k u$ and sir2 by PCR analysis. The $k u$ and sir2 genes containing TAP-tag knock-in cassettes were constructed according to the protocol in Figure 1. The TAP tag was targeted to the C-terminal end of the $k u$ or $\operatorname{sir} 2$ locus, and positive strains were validated by PCR. In the left panel, lanes 1 and 2, PGR results using primers $x$ kia and $x$ kib (lane 1,1.3 kbp TAP-tagged $k u$ locus, lane 2, wild- 
type); lanes 3 and 4, PCR results using primers $x$ kia and $x$ kic (lane 3, $2.9 \mathrm{kbp}$ TAP-tagged $k u$ locus, lane 4, $1.3 \mathrm{kbp}$ wild-type locus), $x$ in the top panel is the $k u$ gene. A wild-type strain was used as a control. The right panel shows the PCR analysis of sir2 using its corresponding primers. $x$ here represents the sir 2 gene. Lanes 1 and 2, PCR results using primers $x$ kia and xkib (lane 1,1.5 kbp TAP-tagged sir2 locus, lane 2, wild-type), lanes 3 and 4, PCR results using primers $x$ kia and $x$ kic (lane 3, 3 kbp TAP-tagged sir2 locus, lane 4, $1.3 \mathrm{kbp}$ wild-type locus).

(TIF)

Figure S2 Western blotting of TAP-tagged Ku and Sir2 protein. The TAP-tagged fusion protein was validated by Western blotting using an anti-ProtA antibody. Only TAP-tag protein was expressed as a control.

(TIF)

Figure S3 Identification of Sir2 as a Ku-binding protein. The Ku-binding partners were obtained by tandem affinity purification of TAP-tagged $\mathrm{Ku}$. Protein complexes were visualized by silver staining after separation by SDS-PAGE. Several specific bands were excised and subjected to mass spectrometry. Lane 1, the TAP tag alone as a control; lane 2, TAP-tagged Ku complex; $\mathrm{M}$, Protein molecular weight marker. This is an independent replication of the TAP experiment.

(TIF)

Figure S4 Protein sequence analysis of various Sir2 proteins. (A) Alignment of Sir2 proteins from bacteria to humans. The $\mathrm{NAD}^{+}$-binding residues are marked by triangles. (B) Phylogenetic relationship of Sir2 among different species. The phylogenetic tree was constructed by the neighbor-joining method using the MEGA 4.1 software. The species abbreviations and the protein accession numbers are: Sc_Sir2, S. cerevisiae Sir2, NP_010242; Mt_Sir2, M. tuberculosis Sir2, NP_215667; Ms_Sir2, M. smegmatis Sir2, YP_889421; Mm_SIRT5, $\bar{M}$. musculus SIRT5, NP_849179; Hs_SIRT5, H. sapiens SIRT5, NP_112534; Ec_ CobB, E. coli CobB, NP_415638.

(TIF)

Figure S5 Construction of the sir2 and $k u$ deletion strains. The $\operatorname{sir} 2$ or $k u$ gene was deleted from the M. smegmatis genome using the mycobacterial recombineering system. The knock-out cassette was generated by overlap extension PCR, in which the two $500 \mathrm{bp}$ sequences fragments flanking each of the ends of ku were fused with the terminal of the Hyg fragment. After the knock-out cassette was transformed into the strains using the recombineering plasmid pJV53, positive recombinants were identified by PCR analysis. In the left panel, lanes 1 and 2, PCR results when primers $x$ koa and $x$ kob were used (lane 1, 690 bp sir2-deletion, lane 2, wild-type), lane 3 and 4, PCR results with primers $x \mathrm{koa}$ and $x \mathrm{koc}$ (lane 3, $2.2 \mathrm{kbp}$ sir2-deficient locus,

\section{References}

1. Daley JM, Palmbos PL, Wu D, Wilson TE (2005) Nonhomologous end joining in yeast. Annu Rev Genet 39: 431-451.

2. Burma S, Chen BP, Chen DJ (2006) Role of non-homologous end joining (NHEJ) in maintaining genomic integrity. DNA Repair (Amst) 5: 1042-1048.

3. Shrivastav M, De Haro LP, Nickoloff JA (2008) Regulation of DNA doublestrand break repair pathway choice. Cell Res 18: 134-147.

4. Sonoda E, Hochegger H, Saberi A, Taniguchi Y, Takeda S (2006) Differential usage of non-homologous end-joining and homologous recombination in double strand break repair. DNA Repair (Amst) 5: 1021-1029.

5. Lees-Miller SP, Meek K (2003) Repair of DNA double strand breaks by nonhomologous end joining. Biochimie 85: 1161-1173.

6. Dudas A, Chovanec M (2004) DNA double-strand break repair by homologous recombination. Mutat Res 566: 131-167.

7. Lieber MR (2008) The mechanism of human nonhomologous DNA end joining. J Biol Chem 283: 1-5. lane $4,1.9 \mathrm{kbp}$ wild-type locus), $x$ in the top panel is the sir2 gene. A wild-type strain was used as a control. The right panel shows the PCR analysis of the $k u$ mutant using corresponding primers. $x$ here indicates the $k u$ gene. Lanes 1 and 2, PCR results using primers $x \mathrm{koa}$ and $x \mathrm{kob}$ (lane 1, 800 bp $k u$-deficient locus, lane 2, wild-type), lanes 3 and 4, PCR results using primers xkoa and xkoc (lane 3, $2.4 \mathrm{kbp} k u$-deficient locus, lane 4, $2.2 \mathrm{kbp}$ wild-type locus).

(TIF)

Figure S6 Southern blot analysis of the sir2 and $k u$ deletion strains. (A) Genomic DNA from M. smegmatis wild-type (lane 1) and sir2 mutant (lane2) strains was digested with PstI and probed with 462-bp gene fragment containing the $5^{\prime}$ flanking region of the sir2 gene. Southern blot analysis revealed the expected fragment of $1700 \mathrm{bp}$ for wild-tpye and larger than $2000 \mathrm{bp}$ for sir2 mutant. (B) Genomic DNA from M. smegmatis wild-type (lane 1) and $k u$ mutant (lane2) strains was digested with PstI and probed with 497-bp gene fragment containing the 5' flanking region of the $k u$ gene. Southern blot analysis revealed the expected fragment of $3200 \mathrm{bp}$ for wild-tpye and larger than 3300 bp for $k u$ mutant.

(TIF)

Table S1 Primers used for generating the TAP-tag knock-in cassette.

(DOC)

Table S2 Primers used for PGR analysis of TAP-tag knock-in strains.

(DOC)

Table S3 Primers used for generating the sir2 or $k u$ knock-out cassettes.

(DOG)

Table S4 Primers used for PGR analysis of sir2 or $k u$ knock-out strains.

(DOC)

Table S5 Primers used in qRT-PGR. (DOC)

\section{Acknowledgments}

We thank Dr D.F. Warner for providing the M. smegmatis $\mathrm{mc}^{2} 155$ strain, Dr G.F. Hatfull for providing the pJV53 recombineering plasmid and Dr M.A Horwitz for providing the pSMT3 expression vector.

\section{Author Contributions}

Conceived and designed the experiments: ZDLJKW LJB XEZ. Performed the experiments: ZDL YNL. Analyzed the data: ZDL JKW LJB XEZ. Contributed reagents/materials/analysis tools: ZDL JKW YNL LJB PX SHW ZPZ YZ XW LS. Wrote the paper: ZDL JKW LJB XEZ.

8. Weterings E, Chen DJ (2008) The endless tale of non-homologous end-joining. Cell Res 18: 114-124.

9. Della M, Palmbos PL, Tseng HM, Tonkin LM, Daley JM, et al. (2004) Mycobacterial $\mathrm{Ku}$ and ligase proteins constitute a two-component NHEJ repair machine. Science 306: 683-685.

10. Gong C, Bongiorno P, Martins A, Stephanou NC, Zhu H, et al. (2005) Mechanism of nonhomologous end-joining in mycobacteria: a low-fidelity repair system driven by $\mathrm{Ku}$, ligase D and ligase C. Nat Struct Mol Biol 12: $304-$ 312.

11. Pitcher RS, Tonkin LM, Green AJ, Doherty AJ (2005) Domain structure of a NHEJ DNA repair ligase from Mycobacterium tuberculosis. J Mol Biol 351: 531-544.

12. Pitcher RS, Brissett NC, Picher AJ, Andrade P, Juarez R, et al. (2007) Structure and function of a mycobacterial NHEJ DNA repair polymerase. J Mol Biol 366: 391-405. 
13. Shuman S, Glickman MS (2007) Bacterial DNA repair by non-homologous end joining. Nat Rev Microbiol 5: 852-861.

14. Pitcher RS, Brissett NC, Doherty AJ (2007) Nonhomologous end-joining in bacteria: a microbial perspective. Annu Rev Microbiol 61: 259-282.

15. Weller GR, Kysela B, Roy R, Tonkin LM, Scanlan E, et al. (2002) Identification of a DNA nonhomologous end-joining complex in bacteria. Science 297: 1686-1689.

16. Bowater R, Doherty AJ (2006) Making ends meet: repairing breaks in bacterial DNA by non-homologous end-joining. PLoS Genet 2: e8.

17. Pitcher RS, Green AJ, Brzostek A, Korycka-Machala M, Dziadek J, et al. (2007) NHEJ protects mycobacteria in stationary phase against the harmful effects of desiccation. DNA Repair (Amst) 6: 1271-1276.

18. Sinha KM, Stephanou NC, Gao F, Glickman MS, Shuman S (2007) Mycobacterial UvrD1 is a $\mathrm{Ku}$-dependent DNA helicase that plays a role in multiple DNA repair events, including double-strand break repair. J Biol Chem 282: 15114-15125.

19. Mizrahi V, Andersen SJ (1998) DNA repair in Mycobacterium tuberculosis. What have we learnt from the genome sequence? Mol Microbiol 29: 1331-1339.

20. Gavin AC, Bosche M, Krause R, Grandi P, Marzioch M, et al. (2002) Functional organization of the yeast proteome by systematic analysis of protein complexes. Nature 415: 141-147.

21. Butland G, Peregrin-Alvarez JM, Li J, Yang W, Yang X, et al. (2005) Interaction network containing conserved and essential protein complexes in Escherichia coli. Nature 433: 531-537.
22. Puig O, Caspary F, Rigaut G, Rutz B, Bouveret E, et al. (2001) The tandem affinity purification (TAP) method: a general procedure of protein complex purification. Methods 24: 218-229.

23. van Kessel JC, Hatfull GF (2007) Recombineering in Mycobacterium tuberculosis. Nat Methods 4: 147-152.

24. Aniukwu J, Glickman MS, Shuman S (2008) The pathways and outcomes of mycobacterial NHEJ depend on the structure of the broken DNA ends. Genes Dev 22: 512-527.

25. Stephanou NC, Gao F, Bongiorno P, Ehrt S, Schnappinger D, et al. (2007) Mycobacterial nonhomologous end joining mediates mutagenic repair of chromosomal double-strand DNA breaks. J Bacteriol 189: 5237-5246.

26. Tsukamoto Y, Kato J, Ikeda H (1997) Silencing factors participate in DNA repair and recombination in Saccharomyces cerevisiae. Nature 388: 900-903.

27. Roy R, Meier B, McAinsh AD, Feldmann HM, Jackson SP (2004) Separationof-function mutants of yeast Ku80 reveal a Yku80p-Sir4p interaction involved in telomeric silencing. J Biol Chem 279: 86-94.

28. Lewis LK, Resnick MA (2000) Tying up loose ends: nonhomologous end-joining in Saccharomyces cerevisiae. Mutat Res 451: 71-89.

29. Lee SE, Paques F, Sylvan J, Haber JE (1999) Role of yeast SIR genes and mating type in directing DNA double-strand breaks to homologous and nonhomologous repair paths. Curr Biol 9: 767-770.

30. Astrom SU, Okamura SM, Rine J (1999) Yeast cell-type regulation of DNA repair. Nature 397: 310. 